\title{
AGOSTINHO E A "DESCOBERTA" \\ DA VONTADE: PRIMEIRO ESTUDO
}

(continuação e fim)

Roberto Hofmeister Pich*

SÍNTESE - Este é um estudo sobre o conceito de vontade na história da filosofia. O centro de interesse está na obra De libero arbitrio, de Agostinho. Tanto se procura descrever a suposta "descoberta" da vontade por Agostinho quanto analisar a coerência do conceito obtido. Trata-se do primeiro de dois estudos sobre a vontade e a liberdade em De libero arbitrio I.

PALAVRAS-CHAVE - Vontade. Liberum arbitrium. Liberdade. Razão. Desejo. Ação. Psicologia da ação moral. Assentimento. Juízo. Erro. Teodicéia.
ABSTRACT - This is a study on the concept of will in the history of philosophy. Its main concern is a work of the young Augustine, namely $D e$ libero arbitrio. Aim of the investigation is both to describe the alleged "discovery" of the will through Augustine and to examine the coherence of such concept. This is the first of two studies on will and freedom according to Augustine in De libero arbitrio $I$.

KEY WORDS - Will. Liberum arbitrium. Freedom. Reason. Action. Psychology of moral action. Assent. Judgement. Error. Theodicy.

\section{Desordem e vontade}

O caminho, porém, que a análise da ordem do ser humano interior tem de tomar, para esclarecer a natureza da vontade e da livre decisão, é, ao final, o entendimento da "desordem" no interior do "estulto". A sabedoria é o senhorio do entendimento ("regnum mentis") ${ }^{1}$ sobre as paixões ("libidines"). Contudo, é possível que o entendimento não exerça o seu senhorio num ser humano particular. A pergunta simples, mas que parece ter inquietado Agostinho sobremaneira, é a seguinte: como é possível que o entendimento não domine os desejos? ${ }^{2}$ Agosti-

\footnotetext{
PUCRS, Porto Alegre.

Cf. De lib. arb. I,10,20: "Sed alia contexamus. Iam enim et regnum mentis humanae humanam esse sapientiam, et eam posse etiam non regnare, compertum est".

Já no escrito De ordine, Agostinho se inquieta com a possibilidade de que, além do sapiens, exista o stultus. Como isso é possível? Ali, a decisão "voluntária" para o mal ainda é um "erro intelectual", a "estultícia" é uma espécie de escuridão ou privação da luz do conhecimento; cf. De ord. II,3,10. Cf. Kurt FLASCH, op. cit., p. 96-7. Cf. também Hermann HÄRING, Das Problem des Bösen in der Theologie, p. 45-50.
}

\begin{tabular}{|l|l|l|l|l|l|}
\hline VERITAS & Porto Alegre & v. 50 & n. 3 & Setembro 2005 & p. 139-157 \\
\hline
\end{tabular}


nho, assim, dá novo conteúdo à mesma pergunta que fora colocada no início da investigação. ${ }^{3}$ Dado que o senhorio das afecções irracionais da alma sobre o entendimento é o quid - a definição - da má ação moral e, ao menos num sentido elementar, a causa mesma da má ação, a pergunta pela origem do mal precisa ser repetida: unde male faciamus? A pergunta central do tratado ainda não recebeu resposta alguma.

Talvez resida por detrás dessa inquietação a formulação de um paradoxo - cf. abaixo a sua formulação exata -, cuja solução exige a existência de uma potência distinta do entendimento e do desejo, isto é, a vontade. Premissa importante para a formulação do paradoxo é a idéia decididamente assumida por Agostinho de que o intelecto é "mais poderoso" ("potentior") que a paixão ("libido"). E, do fato mesmo de o intelecto ser mais poderoso que o desejo ("cupiditas"!), é também justo que ele domine o desejo ("cupiditas"). Aqui, mais uma vez, libido e cupiditas aparecem como sinônimos. É evidente que seria o oposto a algo ordinatissimum que o menos poderoso dominasse o mais poderoso. No entanto, o que faz com que o intelecto seja mais poderoso que o desejo? Ainda que se possa pensar que exista, entre entendimento e desejo, uma superioridade em si da primeira potência sobre a segunda, a superioridade aqui parece ser metafísico-estrutural, da qual se sabe por meio de uma lei eterna. A lei eterna mostra o domínio do entendimento sobre a paixão como uma ordem puramente natural. Que o intelecto comanda a paixão, isso é a natureza do ser humano, e exatamente isso, a natureza, é mais poderoso. ${ }^{4}$

Com terminologia moral, Agostinho afirma, então, que toda virtude (toda mens virtuosa) é superior a todo vício (a toda mens viciosa). Quanto mais elevada a virtude, mais forte e mais imbatível é ela mesma. "Virtude" ainda não é definida por Agostinho, mas ela, como uma disposição desiderativo-cognitiva, se encontra na alma seguramente, quando ao menos o intelecto observa a lei segundo a qual ele conhece a sua boa ordem e o juízo correto para as ações externas. E isso deve significar que o entendimento, assim, tem domínio sobre as afecções e pode sempre dominá-las. Essa mens, além disso, não pode, somente pelas afecções e influências externas, ser dominada. Essa reflexão traz conteúdo para uma nova premissa. Um entendimento que é mais poderoso e pode sempre dominar, porque conhece a natureza, não pode ser dominado por algo menos poderoso. Ele só pode ser dominado por aquilo que é, em si ou estruturalmente, mais poderoso. Ele tem de ser levado às afecções por algo mais poderoso, pois, de si, não faz isso: ele conhece a verdade da natureza. De si os desejos não dominam - isso é contra a natureza -, e os desejos mais fracos não podem enganar o entendimento ao ponto de se tornar subordinado àqueles. ${ }^{5}$

Cf. acima sob 2 e 3.

Cf. De lib. arb. I,10,20: "A. Putasne ista mente, cui regnum in libidines aeterna lege concessum esse cognoscimus, potentiorem esse libidinem? ego enim nullo pacto puto. Neque enim esset ordinatissimum ut impotentiora potentioribus imperarent. Quare necesse arbitror esse ut plus possit mens quam cupiditas, eo ipso quo cupiditati recte iusteque dominatur".

5 Ibidem. 
Além disso, há ainda conteúdo para uma terceira premissa, que, de início, pareceria ser apenas uma observação retórica. Uma mente que exerce o seu senhorio adequado não pode causar que uma outra mente, constituída com as mesmas propriedades, seja sujeitada pela libido. Isso, porém, é de significado central para o argumento: o movimento causador de que uma alma seja sujeitada à libido não pode ser de uma mens para uma outra mens, isto é, não pode ser originado de fora para dentro. Ele tem de ser um movimento da mens para a própria mens. E isso é, de novo, uma premissa central para a idéia geral de que aquilo que sujeita uma mens à libido, e causa com isso uma desordem, não é uma causa exterior, como, por exemplo, Deus ${ }^{6}$ ou um outro ser humano, mas sim o próprio ser humano particular. Nesse sentido, é visto muito bem pelo discípulo Evódio que, quando uma mens tenta tornar uma outra mens virtuosa numa mens viciosa, aquela primeira mens começa um determinado movimento: ela cai de sua justiça e se torna uma mens viciosa. Ela se torna "mais fraca" ("infirmior"), de modo que a mens virtuosa e forte pode tornar-se de si mesma mais fraca. ${ }^{7}$ A premissa consiste, por isso mesmo, na intocabilidade de fora para dentro do ser humano interior: um ser humano ordenado é, de fora para dentro, intocável.

A partir dessas premissas, Agostinho apresenta um argumento decisivo para De libero arbitrio I: trata-se de um argumento para a existência da vontade e da livre-decisão, face ao fenômeno da má ação moral. Agora, o "paradoxo da desordem" ficará claro:

(1) Tudo o que é igual ou superior ("par aut praelatum") à mens que exercita o seu senhorio natural e é virtuosa - isto é, à mens ordenada - não pode tornar essa mesma mens humana uma escrava da paixão ("servam libidinis"), e isso por causa da "justiça" (da ordem justa da natureza humana, "propter iustitiam"). ${ }^{8}$ Nesta primeira premissa - a terceira premissa mencionada acima -, a tese da intocabilidade de fora para dentro do ser humano interior é simplesmente reafirmada.

(2) Tudo o que é inferior à mens tampouco pode torná-la uma escrava das libidines. Motivo para tanto é exatamente a inferioridade/fraqueza ou mesmo o "poder insuficiente" ("infirmitatem") daquilo. ${ }^{9}$ Com isso, faz-se referência às afecções em geral e à faculdade do desejo. Nesta segunda premissa - as premissas primeira e segunda mencionadas acima -, Agostinho resume os motivos da relação de domínio natural entre entendimento e desejo (entre superior e inferior) como potências e mesmo como disposições. Tal relação de domínio é conhecida por todos, através do entendimento, como uma lei natural verdadeira.

$6 \quad$ Cf. De lib. arb. I,11,21: "In praesentia enim scire possumus quaecumque illa natura sit, quam menti virtute pollenti fas est excellere, iniustam esse nullo modo posse. Quare ne ista quidem, tametsi habeat potestatem, coget mentem servire libidini".

Cf. De lib. arb. I,10, 20: "A. Quid? animus iustus, mensque ius proprium imperiumque custodiens, num potest aliam mentem pari aequitate ac virtute regnantem, ex arce deicere, atque libidini subiugare? E. Nullo modo; non solum propter eamden in utraque excellentiam, sed etiam quod a iustitia prior decidet, fietque vitiosa mens, quae aliam facere conabitur, eoque ipso erit infirmior".

8 Cf. De lib. arb. I,11,21: "A. Ergo relinquitur ut quoniam regnanti menti compotique virtutis, quidquid par aut praelatum est, non eam facit servam libidinis propter iustitiam; [...]".

9 Cf. De lib. arb. I,11,21: "A. [...]; quidquid autem inferius non possit hoc facere propter infirmitatem". 
Exatamente neste momento, antes da conclusão, o paradoxo deve ser formulado:

(3) Contudo, existe o mal fático. Há ações - e mesmo disposições do ser humano interior - nas quais o inferior domina o superior, em que a desordem é manifesta. Neste caso, a faculdade desiderativa irracional prevalece sobre a faculdade racional, e as forças desiderativas presentes nas ações particulares são amores como desejos inadequados.

Como a premissa (3) é possível? Agostinho não nega as premissas (1), (2) e (3). No entanto, as premissas (1) e (2) e a premissa (3) são excludentes. Dado que as três premissas são descritivamente verdadeiras, o paradoxo está em que pôr as duas primeiras torna a terceira premissa falsa; pôr a terceira premissa falsifica ou bem uma das duas primeiras ou as duas primeiras premissas em conjunto. As premissas são, porém, verdadeiras. Para que sejam em conjunto possíveis - sobretudo para que a premissa (3) seja verdadeira e possível -, é necessário acrescentar uma premissa posterior, que, ao tornar as três premissas verdadeiras e compatíveis, vale ao mesmo tempo como conclusão do argumento. Fosse ela então uma premissa, ela faria da premissa (3) uma conclusão verdadeira e possível. Assim, a conclusão de Agostinho se assemelha à conclusão de um "argumento transcendental": ela vale como condição necessária de possibilidade, não do "pensamento ou do juízo", mas sim do fenômeno do erro moral, na medida em que determinadas premissas - de psicologia moral descritiva - são aceitas como premissas naturais necessárias e verdadeiras: ${ }^{10}$

(4) Com isso, fica evidente que nenhuma outra realidade ("nulla res alia") faz da mens uma escrava do desejo ("cupiditatis") além da própria vontade ("propria voluntas") e da livre decisão ("liberum arbitrium").

O argumento conclui a existência de uma causa da ação má, uma realidade que, de acordo com determinadas premissas - segundo os limites da filosofia moral estóica que Agostinho conhecia -, tem de existir. Essa causa real é chamada de "voluntas" e de "liberum arbitrium". Na medida em que a alia res do ser humano interior é tratada, a partir deste argumento, inconfundivelmente como a potência determinada da vontade, e as suas propriedades e capacidades de ação são explicadas em conjunto com o liberum arbitrium, ${ }^{12}$ não vejo oposição por que o

${ }^{10}$ Cf. Ross HARRISON, Transcendental arguments, in: Edward CRAIG (ed.), Routledge Encyclopedia of Philosophy, Vol. 9, p. 453: "They are arguments about the preconditions of thought or judgement. They start with a supposition about our thoughts, such as that we have thoughts of some particular kind. A necessary condition for having such thoughts is then derived, followed by a necessary condition for this necessary condition, and so on. Assuming that the first assumption is correct, all its necessary conditions will then have been found also to apply".

${ }^{11}$ Cf. De lib. arb. I,11,21: "A. [...], sicut ea quae inter nos constiterunt docent; nulla res alia mentem cupiditatis comitem faciat, quam propria voluntas et liberum arbitrium". Não é tarefa simples identificar, aqui, qual é o argumento; cf. também F.-J. THONNARD, Introduction, in: Saint AUGUSTINE, Le livre arbitre - Dialogues Philosophiques, p. 505.

${ }_{12}$ Em que medida, em De libero arbitrio I, vontade e livre decisão são explicitamente diferenciadas, cf. Roberto Hofmeister PICH, Agostinho e a "descoberta" da vontade: segundo estudo, [em preparação]. 
argumento não deva ser chamado de "argumento para a existência da vontade". A pergunta "unde male faciamus?" recebe uma primeira resposta, embora esta ainda não seja definitiva; afinal, a mesma questão tem ainda de ser colocada para a vontade mesma: "unde voluntas male faciat?". Isso diz respeito a De libero arbitrio I,12-16 e não será analisado neste ensaio. Antes que seja feita a análise ${ }^{13}$ e sejam tiradas as conclusões mais importantes do argumento acima, ao mesmo tempo do estudo todo, devem ser discutidos os conteúdos concretos da desordem no ser humano. Sem eles, não há como propor uma interpretação coerente do paradoxo da desordem.

A terminologia teológica, no capítulo final da primeira parte de De libero arbitrio I, não é o mais importante, quando é afirmado que, por causa de tal desordem ou de tal pecado - em que a desordem é o pecado psicológico-estrutural na e através da vontade, a saber, a constituição na qual ela se encontra para causar as más ações -, a vontade merece "punições" ("poenas"). ${ }^{14}$ Merece a vontade, causa principal personalizada, punições, então também o espírito sofre de uma punição não pequena. Agostinho oferece uma descrição detalhada do modo como a constituição interior humana se encontra por causa do pecado da vontade. As suas conseqüências, como aquelas de toda constituição psicológico-estrutural específi$\mathrm{ca}$, podem ser somente vícios ou virtudes. ${ }^{15}$ Como um todo, acentua-se que não é uma pequena punição para o espírito que ele seja dominado pela paixão ("libido") e perca a riqueza da virtude ("virtutis opulentia"). ${ }^{16}$ Essa riqueza, no entanto, é primeiramente de natureza cognitiva, ou melhor, de natureza doxástica. Nos quatro casos descritos, a seguir, a constituição viciosa do espírito indica perda de poder cognitivo:

(a) O espírito assente à falsidade ao invés da verdade, defende o falso e reprova logo em seguida ("improbare") o que ele antes havia aprovado ("aprobare"). ${ }^{17}$

(b) O espírito retira o seu assentimento ("assentionem") freqüentemente e não deixa valer motivos racionais claros. Agostinho aponta, desse modo, para uma certa responsabilidade da vontade diante da "incerteza habitual", de maneira que o ser humano interior vivencia uma espécie de "ceticismo de suspensão de juí$\mathrm{ZO}^{\prime \prime}{ }^{18}$

3 Em especial do porquê o conteúdo da premissa posterior (4) ou conclusão do argumento não poder ser outro.

${ }^{14}$ Cf. De lib. arb. I,11,22: "A. Sequitur iam ut tibi videatur iuste illam pro peccato tanto poenas pendere".

15 Isso, naturalmente, reforça a idéia de que o pecado ou a má disposição moral é também um mau hábito fixado.

16 Cf. De lib. arb. I,11,22: "A. Quid ergo? Num ista ipsa poena parva existimanda est, quod ei libido dominatur, exspoliatamque virtutis opulentia, per diversa inopem atque indigentem trahit, [...]".

${ }_{17}$ Cf. De lib. arb. I,1,22: "A. [...], nunc falsa pro veris approbantem, nunc etiam defensitantem, nunc improbantem quae antea probavisset, et nihilominus in alia falsa irruentem; [...]".

${ }^{18}$ Cf. De lib. arb. I,1,22: "A. [...]; nunc assensionem suspendentem suam, et plerumque perspicuas ratiocinationes formidantem; [...]". 
(c) O espírito duvida que possa encontrar, em algum momento, a verdade plena, perdendo-se completamente na "estultícia". O sábio se torna um estulto. ${ }^{19}$

(d) O espírito ora se inclina para a luz do conhecimento, ora se afunda de novo, inconsciente. ${ }^{20}$ Ele é caracterizado, aqui, pela inconstância. O tema aponta, sem receber maior tratamento, para a idéia da divisão das inclinações da vontade: o ser humano é incapaz de permanece junto à verdade conhecida pelo entendimento.

É coerente pensar que todos os vícios "cognitivos" acima mencionados são compreensíveis a partir da não-observação da verdade da lei natural. Em momento algum Agostinho diz que o conhecimento daquela verdade natural está perdido: antes, a lei mesma - surpreendentemente - não é observada! A lei não é seguida, muito embora se saiba que a lei e a ordem existem. Por isso mesmo, aquelas qualificações do espírito ou hábitos são "vícios" dos quais o ser humano é culpado e responsável. Mas, se a responsabilidade é entendida dessa maneira, então ela afasta a possibilidade de que o erro moral resida na ignorância. Antes, visto cognitivamente, ele ganha forma no juízo prático falso, que intermedeia razão e impulso imediato da ação e é causado por certo amor desordenado.

O primeiro grupo de vícios é, com isso, antes prático-doxástico. O contexto de disputa é a origem do mal moral fático. Mesmo funções cognitivas devem ser pensadas, aqui, com este propósito. Tão ou mais decisivo que o conhecimento prático, para a ação moral, é o juízo prático. Todos os hábitos cognitivos, que expressam a "punição" (cf. acima), são compreensíveis a partir de atitudes cognitivas precipuamente judicativas - ou antijudicativas. São vícios práticos da mente entendida como sujeito prático, não da razão meramente. Instabilidade cognitiva e ceticismo cognitivo não dizem respeito ao modo como a lei moral natural da ordem interna é sabida, mas ao modo como ela, no juízo prático para a ação moral, internamente face a determinadas representações intelectuais, ${ }^{21}$ é crida. Vícios doxásticos, ao que tudo indica, primariamente causados pela vontade, dizem respeito ao crer (à "crença" como "belief"), ${ }^{22}$ não ao saber. Um vício doxástico é assim definido: é um hábito de senhorio da vontade ${ }^{23}$ (sic!) sobre o entendimento,

${ }_{19}$ Cf. De lib. arb. I,11,22: "A. [...]; nunc desperantem de tota inventione veritatis, et stultitiae tenebris penitus inhaerentem; [...]".

${ }^{20}$ Cf. De lib. arb. I,11,22: "A. [...]; nunc conantem in lucem intelligendi, rursusque fatigatione decidentem: [...]".

${ }^{21}$ A vontade, na psicologia agostiniana, não é geradora de representações, mas sim "copuladora". Ela as aplica, em seus atos, a partir das faculdades de sentir, imaginar e pensar; cf. De Trinitate XI,7,12. Cf. Étienne GILSON, op. cit., p. 174

22 Classicamente, ao se assentir a uma impressão, tem-se uma crença. A crença é o mesmo evento que assentir. Em epistemologia, os subtipos mais importantes de crença são as meras opiniões e o conhecimento, o assentimento firme às impressões "catalépticas"; cf. Ted BRENNAN, Stoic moral psychology, in: Brad INWOOD (ed.), op. cit., p. 263-265. Além disso, Agostinho definirá correntemente o ato de crer como "pensar com assentimento" ou "fazer uso da mente com assentimento" ("credere est cogitare cum assentione"); cf. De praedestinatione sanctorum II,5. Cf. Stephen MENN, Descartes and Augustine, p. 309-310, nota 7.

${ }^{23}$ Sob esta definição, que segue o papel da vontade na constituição do ser humano interior, não é correto afirmar que, em se dando uma decisão para a "desordem", o "entendimento peca", cf. Carl 
em que a vontade de si é afetada pelos desejos e de si não está em concordância com o entendimento. É sintomático que os vícios prático-doxásticos precedam (cf. abaixo) os vícios prático-morais. Nesse tocante, Agostinho permanece bastante próximo ao esquema psicológico do estoicismo: ações internas e externas são sempre intermediadas por atos cognitivos, isto é, assentimentos. Isso determina o ordenamento interno e o movimento imediato à ação externa. Mas, ao contrário do estoicismo clássico, Agostinho não dá a entender, em nenhum momento, que o equívoco teórico-cognitivo e a contingência das representações e do valor dado aos juízos são como tais a causa de más ações. Não se trata de erros puramente epistêmicos, trata-se de equívocos voluntarístico-doxásticos.

Em De libero arbitrio 1,11,22, modifica-se a descrição dos modos como a corrupção da vontade causa uma constituição viciosa. Agostinho caracteriza, agora, a desordem do espírito em termos prático-morais. Ele aponta para hábitos viciosos que são produzidos por causa da relação entre vontade "corrompida" e desejos. Um vício moral é definido assim: é um hábito de senhorio da vontade (sic!) sobre o desejo, em que a vontade de si é afetada pelos desejos e de si não está em concordância com o entendimento. Quando, por causa da vontade, o senhorio tirânico dos desejos ("regnum cupiditatum") torna confuso e sujeito o espírito e a vida ("totum hominis animum vitamque"), "com todo tipo de tempestades furiosas", a relação entre vontade e afecções também acaba se tornando equivocada:

(a) Ora está o ser humano em temor ("timor"), ora em desejo ("desiderium");

(b) Ora está em ansiedade ("anxietas"), ora em alegria vã e falsa ("inani falsaque laetitia");

(c) Ora está em tormentosa falta daquilo que se ama, ora em cobiça fervente daquilo que não se alcança;

(d) Ora em dor atroz por causa da injustiça sofrida, ora em flamas quentes de vingança. $^{25}$

Creio ser possível reconhecer, nos quatro momentos, as quatro formas básicas das paixões segundo os estóicos, e isso da seguinte forma: (a) medo e desejo, (b)

\footnotetext{
Johann PERL, Kommentar, in: Aurelius AUGUSTINUS, Der freie Wille, p. 199. Quem peca é o ser humano e, nisso, primariamente a instância que se vincula à responsabilidade pelos compromissos internos, isto é, a vontade.

${ }^{24}$ De libero arbitrio I não parece conter remissão às "propatheiai", às "paixões preliminares", reações afetivas como que reflexas, que devem ser imediatamente controladas, a fim de evitar o surgimento de uma paixão. Problemático, para os estóicos, era o fato de que essas reações afetivas pareciam ocorrer sem os juízos que constituem as emoções propriamente. Agostinho, nos Sermones e nas Enarrationes in Psalmos, desenvolve implicacões do cognitivismo estóico e identifica a causa cognitiva das propatheiai na dúvida momentânea. Cf. Sarah C. BYERS, Augustine and the cognitive cause of Stoic 'preliminary passions' (propatheiai), in: Journal of the History of Philosophy, p. 433448.

${ }^{25}$ Cf. De lib. arb. I,11,22: “A. [...]: cum interea cupiditatum illud regnum tyrannice saeviat, et variis contrariisque tempestatibus totum hominis animum vitamque perturbet, hinc timore, inde desiderio; hinc anxietate, inde inani falsaque laetitia; hinc cruciatu rei amissae quae diligebatur, inde ardore, adipiscendae quae non habebatur; hinc acceptae iniuriae doloribus, inde facibus vindicandae: $[\ldots] "$.
} 
desejo e prazer, (c) dor e desejo, (d) dor e desejo. ${ }^{26}$ A desordem - o regnum illius libidinis, por causa da vontade - causa na vontade mesma uma constituição complexa de vícios doxásticos e morais. Em todas essas disposições, é a vontade a causa principal e a potência mais forte. Ela determina o ser humano interior assim como um Deus microcósmico.

\section{Análise do argumento e conclusões}

As conclusões a seguir são provisórias e se limitam a De libero arbitrio I,1-11. Elas se voltam ao ensaio como um todo e em especial ao "paradoxo da desordem":

I. Agostinho ofereceu uma primeira resposta à pergunta "unde male faciamus?". Ele a obtém após uma investigação da psicologia da ação moral. O mal é, na ação e na ordem interna, uma oposição à natureza, mas não é meramente stultitia. ${ }^{27}$ Condição de possibilidade do mesmo é uma potência "além" da natureza. "Natureza" Agostinho identifica na razão e na potência desiderativa, bem como no seu laço psicológico. A potência além da natureza é a vontade, que, como em De civitate Dei XIV será lido, decide - no assentimento ou no "consentimento" ("consentio") ${ }^{28}$ - o caráter moral do impulso desiderativo e, assim, da ação toda. ${ }^{29}$ Somente ali uma teoria da ação moldada pelo estoicismo localiza o

${ }^{26}$ Basicamente, pode-se tomar a dor como a opinião de que algo ruim está presente, o prazer como a opinião de algo bom está presente, o medo como a expectativa irracional de algo ruim para o futuro, o desejo como a necessidade irracional de algo bom para o futuro. Todas essas opiniões são, é claro, falsas a cada vez, dado que se julga algo moralmente indiferente e aparentemente bom ou mau como realmente bom ou mau. O sábio não tem emoções, mas "eupatheiai", "boas emoções", que são, na realidade, a cada vez, episódios prático-judicativos de conhecimento. O sábio estóico, ademais, predica maldade apenas dos vícios, bondade apenas das virtudes; cf. Ted BRENNAN, Stoic moral psychology, in: Brad INWOOD (ed.), op. cit., p. 269-70. Cf. Stoicorum veterum fragmenta III,394s. Se, nos quatro momentos, que resumem as paixões como movimentos desiderativos inadequados da alma, tal que todo movimento seu tende a adquirir e conservar o que toma como bom ou a evitar e descartar o que toma como mau, são descritas formas gerais da corrupção da vontade - como um "bom" ou "mau" amor -, conseqüências viciosas semelhantes podem ser denominadas de maneira mais específica: avaritia e luxuria; ambitio e superbia; invidia e desidia; pervicacia e subiectio. Cf. De lib. arb. I,11,22: “A. [...]: quaquaversum potest coarctare avaritia dissipare luxuria, addicere ambitio, inflare superbia, torquere invidia, desidia sepelire, pervicacia concitare, affilettare subiectio, et quaecumque alia innumerabilia regnum illius libidinis frequentant et exercent? possumusne tandem nullam istam poenam putare, quam, ut cernis, omnes qui non inhaerent sapientiae, necesse est perpeti?". Não há simetria entre esta descrição e a primeira. A correspondência específica de cada uma destas disposições às quatro formas básicas das paixões não me é, como um todo, evidente. Cf. Stoicorum veterum fragmenta III,385s. De qualquer modo, essas disposicões são movimentos livres da alma, a vontade mesma; cf. De civitate Dei XIV,6,41; XIV,7,2. Simo KNUUTTILA, The emergence of the logic of will in Medieval thought, in: Gareth B. MATTHEWS (ed.), The Augustinian tradition, p. 208-9, com base em De civitate Dei IX e XIV, faz referência a uma noção ampla e a uma noção estrita de volição: a ampla se refere a todos os tipos de ações dinâmicas da alma; a restrita se refere a atos do poder dinâmico e controlador na parte superior.

27 Cf. Kurt FLASCH, op. cit., p. 104-105.

28 Sobre "consentio" em De sermone Domini in monte I,35, cf. Esa RANNIKKO, op. cit., p. 86.

${ }^{29}$ Cf. De civitate Dei XIV,6. Cf. também Gerald BONNER, Cupiditas, in: Cornelius MAYER (Hrsg.), Augustinus-Lexikon, p. 166-72, sobre a vontade e a boa ou má cupiditas. 
erro moral: tal papel judicativo é assumido, já no De libero arbitrio I, pela vontade. A direção dada à ação, no impulso desiderativo, é um amor, é uma vontade.

II. Para explicar a má ação moral, Agostinho se dedica às relações entre potência da razão e potência irracional do desejo, tanto no interior do ser humano quanto em relação à disposição da alma face ao mundo. É evidente que Agostinho, através de um procedimento descritivo das ações humanas ou ao menos por força do argumento, aceita a tese da relação de domínio entre entendimento e desejo e a tese da intocabilidade da mente como a própria personalidade. A ambas as teses pode-se relacionar a idéia de natureza, a verdade da lei eterna, que se dirige ao âmbito das potências psicológicas e é como tal conhecida: intocabilidade e domínio da razão são natureza, e isso é acessível a todos. Obviamente, se isso, na ação, é descritivo da "natureza" racional da psyche, isso é de imediato, no plano moral, prescritivo-normativo. Vale como axioma da antiguidade, assim Brennan, que a psicologia e a ética estão ligadas por um certo tipo de naturalismo; a psyche humana perfeitamente representativa pertence ao agente humano perfeitamente ético ${ }^{30}$ A ética jamais está em conflito com a verdadeira natureza da psicologia humana.

III. As teses da intocabilidade e do senhorio natural não são falsas. Naturalmente, elas são, ao final, reinterpretadas, pois a vontade, e então o ser humano ou a mens, será a última instância de intocabilidade e senhorio interno. Como apresentadas no paradoxo, contudo, aquelas premissas não deixam lugar algum para o que é entendido por Agostinho como mal fático no próprio paradoxo - cf. a premissa (3). Ambas as premissas não podem explicar uma constituição verdadeiramente antinatural: com elas somente, a natureza não teria lacunas. $\mathrm{O}$ argumento precisa prever que, segundo as premissas (1) e (2), a razão, na ação e na disposição internas, está no seu melhor estado. Isso parece tanto significar que ela não se encontra em ignorância e coação (pois é "mais forte") quanto exigir inconsistência na idéia de que a razão, por si, torne o mal das ações possível. Afinal, a conclusão ou premissa posterior (4) poderia ser a "perversidade da razão", pela qual ela mesma é responsável: concluir-se-ia que existe uma razão perversa de si mesma.

Isso, porém, não pode ser aceito. Se as premissas (1) e (2) admitissem que a mente se torna, de si, mais fraca, teriam ao fim de invocar a concepção do entendimento "forte" ou "em seu melhor estado" que, porque é igual a si ou mais forte que ele mesmo, pode com isso se tornar mais fraco. Ou ainda: o entendimento, para consigo, não é intocável. A dificuldade, aqui, em que se transferiria à razão o que se costumou referir à vontade, consistiria em defender que é na natureza do entendimento que essa determinação é mesmo visível. A facilidade maior que se verifica na sugestão de que uma faculdade interna mais potente - até então não "descoberta" - abala a faculdade interna da razão é semelhante à maior facilidade de se verificar no assentimento, e não no conhecimento, a fraqueza característica do erro moral. Agostinho, assim, parece localizar na causa cognitiva do assenti-

${ }^{30}$ Cf. Ted BRENNAN, Stoic moral psychology, in: Brad INWOOD (ed.), op. cit., p. 257-259. 
mento a causa do mal das ações, mas a razão, como entendida, não pode ser tal causa. É claro que isso pode remeter-se a certa idéia descritiva que Agostinho tem da razão como faculdade de conhecer - a de que ela (re-)conhece ou apreende cognitivamente, ${ }^{31}$ não julga -, mas pode também conter a idéia, igualmente descritiva, de que Agostinho vê, no conteúdo da premissa (3), uma cisão, na como que simultaneidade, na ação, entre o poder cognitivo do conhecimento e o poder cognitivo de julgar e dar conteúdo intensional ao que é posto pela razão. A. C. Lloyd formulou a concomitância entre conhecer e julgar, na teoria da ação estóica, ao dizer que é errado supor que se decide após ter-se escolhido um curso de ação. Essa suposição implicaria distinção entre escolher algum $X$ e decidir "fazer $\boldsymbol{\Phi}^{\prime}$. Na concepção estóica, o objeto de escolha já tomaria a forma "fazer $\boldsymbol{\Phi}$ " ${ }^{32}$ Como as premissas descritivas (1), (2) e (3) mostram poder cognitivo de conhecimento e poder cognitivo de julgamento cindidos, não pode ser a razão, ali, dadas as premissas (1) e (2), duas vezes a mesma faculdade em como que relação de conseqüência aberrante: "Sabe-se que $p$; logo, crê-se que não-p". O caminho apontado por Agostinho não seria, então, atrativo para solucionar os dois momentos inquietantes do desvio moral, isto é, o equívoco cognitivo e o amor desiderativo aceito na base de movimentos desiderativos irracionais?

IV. A cisão conhecimento-juízo ${ }^{33}$ parece ser o fundamento para a idéia inovadora de que, na ação moral, precisa haver um impulso que se pode genuinamente chamar de "intenção", de ação pessoal autodeterminada "além" da natureza. ${ }^{34}$ A potência da intenção é a "vontade": ela é racional, mas pode ser antinatural ou natural, dependendo de como controla a si e a tudo que está em seu poder. Desse modo, abre-se um novo caminho para a função teórica do conceito de vontade: a linguagem precisa para ela não é nem a da naturalidade nem a da antinaturalidade ou a da irracionalidade, mas a da sobre-naturalidade. O conceito de vontade, assim, como insistiu Bonnie KENT sobre a teoria agostiniana, seria necessário, não só para a psicologia moral descritiva, mas também para fornecer

31 Cf. Stephen MENN, op. cit., p. 311-312

32 Cf. A. C. LLOYD, Emotion and decision in Stoic psychology, in: John M. RIST (ed.), op. cit., p. 245246.

${ }^{33}$ Verdadeiramente, a clássica congruência entre razão e "vontade" é substituída pelo modelo de conflitividade (possível) entre ambas. A radicalização disso se encontra em Confessiones VIII,5,1012. Ademais, é sugestivo pensar que a dissociação de saber e vontade é, ao mesmo tempo, a dissociação de saber e poder: a vontade é poder. Cf. Siegbert PEETZ, Augustin über menschliche Freiheit (Buch V), in: Christoph HORN (Hrsg.), op. cit., p. 70-71.

34 Certas afirmaç̃es sobre De libero arbitrio I em James WETZEL, Augustine and the limits of virtue, 1992, são, com base na minha argumentação, dificilmente aceitáveis. Cf. ibidem, p. 84-5: "In this important but fatally flawed work [... Volitions are as of yet barely distinguishable from cognitions of order, and consequently voluntary movements tend to fade into the natural movements of the created order". Ainda, cf. ibidem, p. 88: "Since Augustine's earlier assimilation of motivation to cognition in De libero arbitrio disallows any handicapping of willing other than by ignorance, there is no way even to formulate weakness of will for the voluntas of book I". Minhas considerações sobre a interpretação de James Wetzel sobre a obra agostiniana em apreço, cf. ibidem, p. 84-98, dariam ocasião a um ensaio inteiro. 
sentido à linguagem do dever. ${ }^{35}$ É para explicar a responsabilidade que se precisa pôr o conceito de vontade, idéia igualmente presente na experiência de estima e de rejeição de ações de indivíduos: agir por motivações - o amor agostiniano e o dever kantiano -, e não por condicionamento, é condição necessária para o estatuto de agente moral. A distinção da semântica da vontade e da natureza funda a linguagem da moral.

V. Não há dúvida de que existe, para Agostinho, a terceira instância de atividade da psyche invocada no estudo de Albrecht Dihle. ${ }^{36}$ Ela é uma potência ativa e desiderativa, caso "amor" signifique um poder interno de movimento e intensidade que dispõe de tudo. E, sem dúvida, essa potência é cognitiva, e isso em dois sentidos. A voluntas é consciente do saber do entendimento, do contrário ela não poderia estar ou deixar de estar em concordância com o mesmo. Por esse motivo, ações da vontade são conscientes ainda num segundo modo: ela é conscientemente pro ou contra o saber da razão. ${ }^{37}$

Em De libero arbitrio I,1-11, o "critério de espontaneidade" - de que a potência que permite, em plena consciência, a decisão pelo falso não é, junto com as suas ações, posteriormente dedutível, ou seja, nenhuma outra grandeza a determina na escolha consciente do falso - não é abordado. ${ }^{38}$ Caso se discuta o "critério de consciência", igualmente apresentado por Christoph HORN, como condição necessária para um conceito coerente de vontade, ${ }^{39}$ parece-me possível já fazer algumas afirmações. É correto dizer que uma ação certa ou errada resulta da racionalidade ou da irracionalidade da ordem, definidas como pressuposições para a ação da vontade. É também correto que a vontade, nisso, age (se decide) sempre com uma consciência que - minha formulação - é tanto respectiva à verdadeira racionalidade da lei eterna quanto à direção do motivo específico da vontade. Essa consciência dupla é necessária para a ação que Agostinho esquematiza, num sentido que deve ser complementar à argumentação de Christoph Horn.

Certamente, a consciência da lei racional evita que a ética conduza a uma espécie de decisionismo ou a um voluntarismo. ${ }^{40}$ A decisão pelo irracional é irracional e contrária à natureza por causa do conhecimento e da consciência da lei eterna, de modo que o conceito de vontade agostiniano admite um caráter norma-

35 Cf. Bonnie KENT, Augustine's ethics, in: Eleonore STUMP and Norman KRETZMANN (eds.), op. cit., p. 221-223. Cf. também De civitate Dei XII,7-8 e XIV,11-15.

36 Cf., na primeira parte desta investigação, Roberto Hofmeister PICH, Agostinho e a "descoberta" da vontade: primeiro estudo, in: Veritas, 50 (2005):2, a nota 11.

37 A impossibilidade, no pensamento platônico, de um poder e uma concepção de liberdade em que 0 agente conhece o mal pelo que ele é (pressupondo o conhecimento do bem), escolhendo, nisso, o mal por ele mesmo, consciente e livremente, foi bem apontada por tham DILMAN, Free will. An historical and philosophical introduction, p. 78-9. Sobre o erro na apreciação racional e o assentimento da vontade, cf. também John RIST, Faith and reason, in: Eleonore STUMP and Norman KRETZMANN (eds.), The Cambridge Companion to Augustine, p. 36-37.

${ }^{38}$ Cf. Christoph HORN, Augustinus und die Entstehung des philosophischen Willensbegriffs, op. cit., p. $116 \mathrm{~s}$.

39 Ibidem

40 Cf. também Christoph HORN, Wille I. Antike, in: Historisches Wörterbuch der Philosophie, Band 12, p. 768. 
tivo às suas funções morais. Com isso, seriam exigidas, na ética, consciência e racionalidade na ação volitiva - exigências em plena concordância com De libero arbitrio I. Ao mesmo tempo, porém, a dupla consciência, presente no critério de consciência de Christoph Horn, é somente possível, quando a vontade assume, na ordem e nos hábitos cognitivos e morais causados por ela, o papel voluntarísticodoxástico do assentimento. Dessa forma, a dupla consciência exige uma diferença cognitiva entre saber e crer no juízo prático antes da ação: o saber inteiramente obtido num silogismo prático que conclui a verdade de "fazer $\boldsymbol{\Phi}$ " é distinto do juízo para o impulso da ação "fazer $\boldsymbol{\Phi}$ ". "Saber", assim, pertence primariamente ao entendimento e secundariamente à vontade em consciência; "crer", porém, um "saber" ou um "não-saber" querido, ${ }^{41}$ pertence primariamente à vontade em consciência e secundariamente ao entendimento. ${ }^{42}$ Somente assim é possível que alguém aja em consciência dupla. Apenas assim a consciência inclui também a responsabilidade cognitiva e evita a ignorância como motivo da má ação, tal como quando alguém diz: "Sei que $p$; porém, creio que não-p", em liberdade semelhante à do crente, que, passível, não de imoralidade, mas sim de infidelidade, diz "não sei se $p$; porém, creio que $p$ ". ${ }^{43}$

VI. Finalmente, se o paradoxo da desordem foi corretamente exposto, uma prova da existência da vontade não precisa ser puramente descritiva. O primeiro argumento de Agostinho para a existência da vontade, um marco na história do conceito, eu creio, não é um exemplar de "cogito-like arguments". Nestes, a existência da vontade, por introspecção e na base de contradições e/ou evidências performativas, seria imediata e evidente. ${ }^{44}$ Seja como for, o presente estudo não apresentou prova definitiva da vontade como causa do mal, tampouco uma prova da liberdade da vontade, que devem ter ocasião na segunda parte de De libero arbitrio I. ${ }^{45}$ Mas, no que foi apresentado sobre a descoberta da vontade, já há dificuldades suficientes. Trata-se, sim, da "descoberta" da vontade como potência da alma: afinal, "descobre-se" o que já existe como constitutivo; "inventa-se", no máximo, um conceito e uma teoria da vontade. Esta, porém, está entre as solu-

${ }^{41}$ Cf. Joseph MAUSBACH, Die Ethik des Heiligen Augustinus. Zweiter (Schluss-)Band: die sittliche Befähigung des Menschen und ihre Verwirklichung, p. 239.

42 Neste estudo, não há comprometimento com a teoria de que a vontade controla todos os processos cognitivos da alma. A busca de conhecimento, de modo exemplar de autoconhecimento, é guiada pela vontade como amor na atividade cognitiva. A vontade determina a direção e a intensidade da intenção de conhecimento. Cf. Alfred SCHÖPF, Augustinus - Einführung in sein Philosophieren, p. 49; Gerard O'DALY, Augustine's philosophy of mind, p. 210-1. Cf. De Trinitate IX,18; X,11; XI,2; $\mathrm{XV}$,43. Tampouco se pode discutir, aqui, o tópico complexo da explicação do mal em Agostinho como a base da teoria do erro epistêmico em Descartes (cf. Meditação IV). Quanto a esta, Descartes poderia ser interpretado como adequando a teoria geral do juízo a uma teoria geral da ação; cf. Stephen MENN, op. cit., p. 302-10. É de qualquer modo notório que, se o assentimento ou o juízo é formalmente um ato da vontade, este mesmo terá de ser definido como singularmente livre.

43 Sobre a voluntariedade do ato de crer, segundo Agostinho, cf. Esa RANNIKKO, op. cit., p. 46s.

44 Sobre essa família de argumentos e a existência da vontade, cf. Simon HARRISON, Do we have a will? Augustine's way into the will, in: Gareth B. MATTHEWS (ed.), The Augustinian tradition, p. 199s. Exemplo de tal evidência e imediaticidade seria Confessiones VII,3,5.

45 Isto é, De libero arbitrio I,12-16. Cf. Roberto Hofmeister PICH, Agostinho e a "descoberta" da vontade: segundo estudo, [em preparação]. 
ções simples. Em se tratando do tema da vontade e da livre decisão, toda e qualquer pesquisa com algum grau de pretensão vem a se tornar, na maioria das vezes involuntariamente, controvérsia pura.

\section{Referências}

\section{Fontes}

ARISTOTLE. Nichomachean Ethics. Translation, introduction, and commentary by Christopher Rowe and Sarah Broadie. Oxford, Oxford University Press, 2002.

AUGUSTINE, Saint. Le livre arbitre. In: AUGUSTINE, Saint. Dialogues Philosophiques. Paris, Desclée de Brouwer, 1954, p. 509-680.

AUGUSTINE, Saint. On free choice of the will. Translated by Anna S. Benjamin and L. H. Hackstaff. Indianapolis/New York, The Bobbs-Merril Company, 1964.

— . Translated by Thomas Williams. Indianapolis/Cambridge, Hackett Publishing Company, 1993.

AUGUSTINUS, Aurelius. Der freie Wille. Übertragen von Carl Johann Perl. Zweite Auflage. Paderborn, Ferdinand Schöningh, 1954

Vom freien Willen. In: AUGUSTINUS, Aurelius. Theologische Frühschriften - Vom freien Willen, Von der wahren Religion. Lateinisch-Deutsch. Übersetzt und erläutert von Wilhelm Thimme. Zürich/Stuttgart, Artemis Verlag, 1962, p. 29-363.

AUGUSTINUS, Sanctus Aurelius. Confessionum Libri XIII. In: AUGUSTINUS, Sanctus Aurelius. Aurelii Augustini Opera. Editio altera. Corpus Christianorum Series Latina XXVII. Turnholti, Typographi Brepols Editores Pontificii, 1990.

De civitate Dei - Libri I-X (Aurelii Augustini Opera Pars XIV,1). Corpus Christianorum Series Latina XLVII. Turnholti, Typographi Brepols Editores Pontificii, 1955.

. De civitate Dei - Libri XI-XXII (Aurelii Augustini Opera Pars XIV,2). Corpus Christianorum Series Latina XLVIII. Turnholti, Typographi Brepols Editores Pontificii, 1955.

. De diversis quaestionibus octoginta tribus. In: AUGUSTINUS, Sanctus Aurelius. Aurelii Augustini Opera. Corpus Christianorum Series Latina XLIV A. Turnholti, Typographi Brepols Editores Pontificii, 1975, p. 1-249.

De doctrina christiana Libri IV. In: AUGUSTINUS, Sanctus Aurelius. Aurelii Augustini Opera. Corpus Christianorum Series Latina XXXII. Turnholti, Typographi Brepols Editores Pontificii, 1967, p. 1167.

De libero arbitrio Libri III. In: AUGUSTINUS, Sanctus Aurelius. Aurelii Augustini Opera. Corpus Christianorum Series Latina XXIX. Turnholti, Typographi Brepols Editores Pontificii, 1970, p. 209-321.

. De ordine Libri II. In: AUGUSTINUS, Sanctus Aurelius. Aurelii Augustini Opera. Corpus Christianorum Series Latina XXIX. Turnholti, Typographi Brepols Editores Pontificii, 1970, p. 87-137.

. De Trinitate - Libri I-XII (Aurelii Augustini Opera Pars XVI,1). Corpus Christianorum Series Latina L. Turnholti, Typographi Brepols Editores Pontificii, 1968.

De Trinitate - Libri XIII-XV (Aurelii Augustini Opera Pars XVI,2). Corpus Christianorum Series Latina L A. Turnholti, Typographi Brepols Editores Pontificii, 1968.

Retractationum Libri II. In: AUGUSTINUS, Sanctus Aurelius. Aurelii Augustini Opera. Corpus Christianorum Series Latina LVII. Turnholti, Typographi Brepols Editores Pontificii, 1984.

CICERO. De officiis. With an English translation by Walter Miller. Cambridge/London, Harvard University Press, William Heinemann, 1975. 
EPICTETUS. Discourses - Books I and II. The Discourses as reported by Arrian, The Manual, and Fragments. With an English translation by W. A. Oldfather. The Loeb Classical Library. London/Cambridge, William Heinemann/Harvard University Press, 1961.

Discourses - Books III and IV, The Manual, and Fragments. The Discourses as reported by Arrian, The Manual, and Fragments. With an English translation by W. A. Oldfather. The Loeb Classical Library. London/Cambridge, William Heinemann/Harvard University Press, 1966.

LUCRETIUS. De rerum natura - Libri sex. In: BAILEY, Cyril (ed.). Titi Lucretii Cari De rerum natura Libri sex - Volume I: Prolegomena, text and critical apparatus, translation. Oxford, Clarendon Press, 1947 (repr. 1963).

SENECA. Seneca ad Lucilium epistulae morales. With an English translation by Richard M. Gummere. London/Cambridge, William Heinemman, Harvard University Press, Vol. I, 1967.

Seneca ad Lucilium epistulae morales. With an English translation by Richard M. Gummere. London/Cambridge, William Heinemman, Harvard University Press, Vol. III, 1962.

VON ARNIM, Johannes (Hrsg.). Stoicorum veterum fragmenta. Volumen II - Chrysippi fragmenta logica et physica. Editio stereotypa editionis primae (MCMIII). Stuttgart, B. G. Teubner, 1964.

Stoicorum veterum fragmenta. Volumen III - Chrysippi fragmenta moralia, fragmenta sucessorum Chrysippi. Editio stereotypa editionis primae (MCMIII). Stuttgart, B. G. Teubner, 1968.

\section{Literatura secundária}

BABCOCK, William S. Introduction. In: BABCOCK, William S. (ed.). The ethics of St. Augustine. Atlanta, Scholars Press, 1991, p. 5-10.

BERLINGER, Rudolph. Augustins dialogische Metaphysik. Frankfurt am Main, Vittorio Klostermann, 1962.

BETTETINI, Maria. Die Wahl der Engel. Übel, Materie und Willensfreiheit (Buch XI-XII). In: HORN, Christoph (Hrsg.). Augustinus - De civitate Dei. Klassiker Auslegen Band 11. Berlin, Akademie Verlag, 1997, p. 131-155.

BOBZIEN, Suzanne. Determinism and freedom in Stoic philosophy. Oxford, Clarendon Press, 1998.

BONHÖFFER, Adolf. Die Ethik des Stoikers Epictet. Anhang: Exkurse über einige wichtige Punkte der stoischen Ethik. Stuttgart, Verlag von Ferdinand Enke, 1894.

BONNER, Gerald. Cupiditas. In: MAYER, Cornelius (Hrsg.). Augustinus-Lexikon. Basel, Schwabe \& Co., 1996-2002, Band II, p. 166-172.

BOUMAN, Johan. Augustinus - Lebensweg und Theologie. Giessen/Basel, Brunnen Verlag, 1987.

BOYANCÉ, Pierre. Die Stoa in Rom. In: MAURACH, Gregor (Hrsg.). Seneca als Philosoph. Darmstadt, Wissenschaftliche Buchgesellschaft, 1975, p. 38-52.

BRACHTENDORF, Johannes. Die Struktur des menschlichen Geistes nach Augustinus. Selbstreflexion und Erkenntnis Gottes in "De Trinitate". Hamburg, Felix Meiner, 2000.

BRENNAN, Ted. Stoic moral psychology. In: INWOOD, Brad (ed.). The Cambridge Companion to the Stoics. Cambridge, Cambridge University Press, 2003, p. 257-294.

BYERS, Sarah C. Augustine and the cognitive cause of Stoic 'preliminary passions' (propatheiai). In: Journal of the History of Philosophy. 41 (2003):4, p. 433-448.

CALLAHAN, John F. Augustine and the Greek philosophers. The Saint Augustine Lecture 1964. Villanova, Villanova University Press, 1967.

CAVARNOS, John P. The relation of body and soul in the thought of Gregory of Nyssa. In: DÖRRIE, Heinrich; ALTENBURGER, Margarete und SCHRAMM, Uta (Hrsg.). Gregor von Nyssa und die Philoso- 
phie. Zweites Internationales Kolloquium über Gregor von Nyssa Freckenhorst bei Münster, 18-23 September 1972. Leiden, Brill, 1976, p. 61-78.

CHROUST, Anton-Hermann. The fundamental ideas in St. Augustine's philosophy of law. In: The American Journal of Jurisprudence. 18 (1973), p. 57-79.

COLISH, Marcia L. The Stoic tradition from Antiquity to the Early Middle Ages - II. Stoicism in Christian Latin thought through the Sixth Century. Leiden, E. J. Brill. 1985 (second impression with addenda and corrigenda, Leiden, E. J. Brill, 1990)

COOPER, John M. Posidonius on emotions. In: COOPER, John M. Reason and emotion. Essays on Ancient moral psychology and ethical theory. Princeton, Princeton University Press, 1999, p. 449-84.

CORETH, Emerich. Vom Sinn der Freiheit. Innsbruck-Wien, Tyrolia-Verlag, 1985.

DENNETT, Daniel C. La libertad de acción. Un análisis de la exigencia del libre albedrío. Barcelona, Gedisa Editorial, 1992.

DIHLE, Albrecht. Die Vorstellung vom Willen in der Antike. Göttingen, Vandenhoeck \& Ruprecht, 1985 (original inglês: The theory of will in classical antiquity. Berkeley/Los Angeles/London, University of California Press, 1982).

DILMAN, Ilham. Free will. An historical and philosophical introduction. London, Routledge, 1999.

ESCRIBANO-ALBERCA, Ignacio. Die spätantike Entdeckung des inneren Menschen und deren Integration durch Gregor. In: DÖRRIE, Heinrich; ALTENBURGER, Margarete und SCHRAMM, Uta (Hrsg.). Gregor von Nyssa und die Philosophie. Zweites Internationales Kolloquium über Gregor von Nyssa Freckenhorst bei Münster, 18-23 September 1972. Leiden, Brill, 1976, p. 43-60.

EVANS, G. R. Augustine on evil. Cambridge, Cambridge University Press, 1982 (repr. paperback edition 1993).

FLASCH, Kurt. Augustin. Einfuhrung in sein Denken. Stuttgart, Philipp Reclam, 1994.

FRANKFURT, Harry G. Alternate possibilities and moral responsibility. In: FRANKFURT, Harry G. The importance of what we care about. Cambridge, Cambridge University Press, 1988 (repr. 1997), p. 1-10.

FURLEY, D. J. Aristotle on the voluntary. In: BARNES, Jonathan; SCHOFIELD, Malcolm and SORABJI, Richard (eds.). Articles on Aristotle 2. Ethics \& Politics. London, Duckworth, 1977, p. 47-60.

GARCÍA RÚA, José Luis. El sentido de la interioridad en Seneca. Contribucion al estudio del concepto de "modernidad". Granada, Departamento de Filosofia/Universidad de Granada, s.d.

GEERLINGS, Wilhelm. Augustinus - Leben und Werk. Eine bibliographische Einführung. Paderborn, Ferdinand Schöningh, 2002

GILL, Christopher. The school in the Roman imperial period. In: INWOOD, Brad (ed.). The Cambridge Companion to the Stoics. Cambridge, Cambridge University Press, 2003, p. 33-58.

GILSON, Étienne. Introduction à l'Étude de Saint Augustin. Quatrième édition. Paris, Librairie Philosophique J. Vrin, 1969.

HACKSTAFF, L. H. Introduction to Saint Augustine - On free choice of the will. In: AUGUSTINE, Saint. On free choice of the will. Translated by Anna S. Benjamin and L. H. Hackstaff. Indianapolis/New York, The Bobbs-Merril Company, 1964, p. ix-xxix.

HÄRING, Hermann. Das Problem des Bösen in der Theologie. Darmstadt, Wissenschaftliche Buchgesellschaft, 1985

HARRISON, Ross. Transcendental arguments. In: CRAIG, Edward (ed.). Routledge Encyclopedia of Philosophy. London/New York, Routledge, 1998, Vol. 9, p. 452-454.

HARRISON, Simon. Do we have a will? Augustine's way into the will. In: MATTHEWS, Gareth B. (ed.). The Augustinian tradition. Berkeley, Los Angeles, London, University of California Press, p. 195-205. 
HÖK, Gösta. Augustin und die antike Tugendlehre. In: Kerygma und Dogma. 6 (1960), p. 104-130.

HONDERICH, Ted. How free are you? The determinism problem. Oxford/New York, Oxford University Press, 1993.

HORN, Christoph. Augustinus und die Entstehung des philosophischen Willensbegriffs. In: Zeitschrift für Philosophische Forschung. 50 (1996), p. 113-132.

. Wille I. Antike. In: Historisches Wörterbuch der Philosophie. Darmstadt, Wissenschaftliche Buchgesellschaft, 1998, Band 12, p. 763-769.

INWOOD, Brad. Epictetus. In: CRAIG, Edward (ed.). Routledge Encyclopedia of Philosophy. London/New York, Routledge, 1998, Vol. 3, p. 337-339.

IRWIN, Terence. Who discovered the will? In: Philosophical Perspectives. 6 (1992), p. 453-473.

JEDIN, Christoph. Willensfreiheit bei Aristoteles? Göttingen, Vandenhoeck \& Ruprecht, 2000.

KAHN, Charles H. Discovering the will: from Aristotle to Augustine. In: DILLON, John M. and LONG, A. A. (eds.). The question of "eclecticism" - Studies in later Greek philosophy. Berkeley, University of California Press, 1988, p. 234-259.

KANE, Robert. Introduction: the contours of contemporary free will debates. In: KANE, Robert (ed.). The Oxford Handbook of Free Will. Oxford, Oxford University Press, 2002, p. 3-41.

KANE, Robert (ed.). The Oxford Handbook of Free Will. Oxford, Oxford University Press, 2002.

KENNY, Anthony. Aristotle's theory of the will. New Haven, Yale University Press, 1979.

KENT, Bonnie. Augustine's ethics. In: STUMP, Eleonore and KRETZMANN, Norman (eds.). The Cambridge Companion to Augustine. Cambridge, Cambridge University Press, 2001, p. 205-233.

KIDD, I. G. Posidonius on emotions. In: LONG, A. A. (ed.). Problems in stoicism. Reprinted. London, The Athlone Press, 1996, p. 200-215.

Stoic intermediates and the end of man. In: DILLON, John M. and LONG, A. A. The question of "eclecticism" - Studies in later Greek philosophy. Berkeley, University of California Press, p. 150-172. KIRWAN, Christopher. Augustine. London/New York, Routledge, 1989.

KNUUTTILA, Simo. The emergence of the logic of will in Medieval thought. MATTHEWS, Gareth B. (ed.). The Augustinian tradition. Berkeley, Los Angeles, London, University of California Press, p. 206221

KÖNIG, Eckard. Augustinus Philosophus. Christlicher Glaube und philosophisches Denken in den Frühschriften Augustins. München, Wilhelm Fink, 1970.

KOROLEC, John. Free will and free choice. In: KRETZMANN, Norman; KENNY, Anthony and PINBORG, Jan (eds.). The Cambridge History of Later Medieval Philosophy. From the rediscovery of Aristotle to the disintegration of scholasticism 1100-1600. Cambridge, Cambridge University Press, 1982, p. 629-641.

KRIEGER, Gerhard und WINGENDORF, Ralf. Christsein und Gesetz: Augustinus als Theoretiker des Naturrechts (Buch XIX). In: HORN, Christoph (Hrsg.). Augustinus - De civitate Dei. Klassiker Auslegen 11. Berlin, Akademie Verlag, 1997, p. 235-258.

LABOWSKI, Lotte. Die Ethik des Panaitios. Untersuchungen zur Geschichte des decorum bei Cicero und Horaz. Leipzig, Felix Meiner Verlag, 1934.

LAMBERIGTS, Mathijs. A critical evaluation of critiques of Augustine's view of sexuality. In: DODARO, Robert and LAWLESS, George (eds.), Augustine and his critics. Essays in honour of Gerald Bonner. London/New York, Routledge, 2000, p. 176-197. 
LEROUX, Georges. Human freedom in the thought of Plotinus. In: GERSON, Lloyd P. (ed.). The Cambridge Companion to Plotinus. Reprinted with corrections. Cambridge, Cambridge University Press, 1999, p. 292-314.

LLOYD, A. C. Emotion and decision in Stoic psychology. In: RIST, John M. (ed.). The Stoics. Berkeley/Los Angeles/London, University of California Press, 1978, p. 233-246.

LONG, A. A. Freedom and determinism in the Stoic theory of human action. In: LONG, A. A. (ed.). Problems in stoicism. Reprinted. London, The Athlone Press, 1996, p. 173-199.

MacDONALD, Scott. Primal sin. In: MATTHEWS, Gareth B. (ed.). The Augustinian tradition. Berkeley, Los Angeles, London, University of California Press, p. 110-39.

MANN, William E. Inner-life ethics. In: MATTHEWS, Gareth B. (ed.). The Augustinian tradition. Berkeley, Los Angeles, London, University of California Press, p. 140-165.

MARKUS, R. A. Marius Victorinus and Augustine. In: ARMSTRONG, A. H. (ed.). The Cambridge History of Later Greek and Early Medieval Philosophy. Cambridge, Cambridge University Press, 1970, p. 331-419.

MATHEWES, Charles. Evil and the Augustinian tradition. Cambridge, Cambridge University Press, 2001.

MAUSBACH, Joseph. Die Ethik des heiligen Augustinus - Erster Band: Die sittliche Ordnung und ihre Grundlagen. Zweite, vermehrte Auflage. Freiburg im Breisgau, Herder, 1929.

Die Ethik des Heiligen Augustinus - Zweiter (Schluss-)Band: Die sittliche Befähigung des Menschen und ihre Verwirklichung. Zweite, vermehrte Auflage. Freiburg im Breisgau, Herder, 1929.

McKEEVER, Martin J. The cardinal desiderative power of the self-ordering subject. An ethical exegesis of Voluntas in Augustine's De Libero Arbitrio. Roma, Pontifica Universitas Lateranensis, 1995.

MENN, Stephen. Descartes and Augustine. Cambridge, Cambridge University Press, 1998.

MERLAN, P. Greek Part I - Greek philosophy from Plato to Plotinus. In: ARMSTRONG, A. H. (ed.). The Cambridge History of Later Greek and Early Medieval Philosophy. Cambridge, Cambridge University Press, 1970, p. 11-132.

MEYER, Susan Sauvé. Moral responsibility: Aristotle and after. In: EVERSON, Stephen (ed.). Ethics Companions to ancient thought 4. Cambridge, Cambridge University Press, 1998, p. 221-240.

NETTO, Francisco Benjamin de Souza. Agostinho: a ética. In: DE BONI, Luis Alberto (org.). Idade Média: Ética e Política. 2. ed. Coleção Filosofia 38. Porto Alegre, Edipucrs, 1996, p. 41-56.

O'CONNELL, Robert J. De libero arbitrio I: stoicism revisited. In: Augustinian Studies. 1 (1970), p. 4968.

O'DALY, Gerard. Augustine's philosophy of mind. Berkeley/Los Angeles, University of California Press, 1987.

Appetitus. In: MAYER, Cornelius (Hrsg.). Augustinus-Lexikon. Basel, Verlag Schwabe \& Co., 1986-1994, Band I, p. 420-423.

PEETZ, Siegbert. Augustin über menschliche Freiheit (Buch V). In: HORN, Christoph (Hrsg.). Augustinus - De civitate Dei. Klassiker Auslegen Band 11. Berlin, Akademie Verlag, 1997, p. $63-86$.

PERL, Carl Johann. Kommentar. In: AUGUSTINUS, Aurelius. Der freie Wille. Übertragen von Carl Johann Perl. Zweite Auflage. Paderborn, Ferdinand Schöningh, 1954, p. 189-246.

. Vorwort. In: AUGUSTINUS, Aurelius. Der freie Wille. Übertragen von Carl Johann Perl. Zweite Auflage. Paderborn, Ferdinand Schöningh, 1954, p. vii-xvi.

PICH, Roberto Hofmeister. Agostinho e o enigma da liberdade. In: Cult - Revista de Ciências Humanas, São Paulo, p. 45-47, 2003. 
RANNIKKO, Esa. Liberum arbitrium and necessitas. A philosophical inquiry into Augustine's conception of the will. Helsinki, Luther-Agricola-Society, 1997.

REESOR, Margaret E. The nature of man in early Stoic philosophy. London, Duckworth, 1989.

REINHARDT, Karl. Poseidonios von Apameia. Der Rhodier genannt. Stuttgart, Alfred Druckenmüller Verlag, 1954, p. 560-826.

RIEF, Josef. Der Ordobegriff des jungen Augustins. Paderborn, Ferdinand Schöningh, 1962

RIST, John M. Augustine. Cambridge, Cambridge University Press, 1994.

. Faith and reason. In: STUMP, Eleonore and KRETZMANN, Norman (eds.). The Cambridge Companion to Augustine. Cambridge, Cambridge University Press, 2001, p. 26-39.

. Stoic philosophy. Cambridge, Cambridge University Press, 1969.

SCHÖPF, Alfred. Augustinus - Einführung in sein Philosophieren. Freiburg/München, Verlag Karl Alber, 1970.

SCHOFIELD, Malcolm. Stoic ethics. In: INWOOD, Brad (ed.). The Cambridge Companion to the StoicS. Cambridge, Cambridge University Press, 2003, p. 233-256.

SEDLEY, David. The school, from Zeno to Arius Didymus. In: INWOOD, Brad (ed.). The Cambridge Companion to the Stoics. Cambridge, Cambridge University Press, 2003, p. 7-32.

SÉRVULO DA CUNHA, Mariana Palozzi. O movimento da alma. A invenção por Agostinho do conceito de vontade. Coleção Filosofia 123. Porto Alegre, Edipucrs, 2001.

SPANNEUT, M. Epiktet. In: Reallexikon für Antike und Christentum. Stuttgart, Hiersemann Verlag, 1954, Band V, p. 599-681.

STEINMANN, Kurt. Nachwort. In: EPIKTET. Handbüchlein der Moral. Übersetzt und herausgeben von Kurt Steinmann. Griechisch/Deutsch. Stuttgart, Reclam, 1992, p. 94-106.

STRAWSON, Galen. Free will. In: CRAIG, Edward (ed.). Routledge Encyclopedia of Philosophy. New York/London, Routledge, 1998, Vol. 3, p. 743-753.

STUMP, Eleonore. Augustine on free will. In: STUMP, Eleonore and KRETZMANN, Norman (eds.). The Cambridge Companion to Augustine. Cambridge, Cambridge University Press, 2001, p. 124-147.

THIMME, Wilhelm. Übersetzung und Erläuterungen. In: AUGUSTINUS, Aurelius. Theologische Frühschriften - Vom freien Willen, Von der wahren Religion. Lateinisch-Deutsch. Übersetzt und erläutert von Wilhelm Thimme. Zürich/Stuttgart, Artemis Verlag, 1962, p. 29-363.

THONNARD, F.-J. Introduction. In: AUGUSTINE, Saint. Le livre arbitre - Dialogues Philosophiques. Paris, Desclée de Brouwer, 1954, p. 505-508.

TOMBERLIN, James E. (ed.). Philosophical perspectives, 14, Action and freedom, 2000. Oxford, Blackwell Publishers, 2000

TRAPPE, T. Streben. In: Historisches Wörterbuch der Philosophie. Darmstadt, Wissenschaftliche Buchgesellschaft, 1998, Band 10, p. 269-296.

VEYNE, Paul. Weisheit und Altruismus. Eine Einführung in die Philosophie Senecas. Frankfurt am Main, Fischer Taschenbuch Verlag, 1993.

WATSON, Gerard. The natural law and stoicism. In: LONG, A. A. (ed.). Problems in stoicism. Reprinted. London, The Athlone Press, 1996, p. 216-238.

WETZEL, James. Augustine and the limits of virtue. Cambridge, Cambridge University Press, 1992.

Snares of truth - Augustine on free will and predestination. In: DODARO, Robert and LAWLESS, George (eds.), Augustine and his critics. Essays in honour of Gerald Bonner. London/New York, Routledge, 2000, p. 124-141. 
WILPERT, Paul. Begierde. In: Reallexikon für Antike und Christentum. Stuttgart, Hiersemann Verlag, 1954, Band II, p. 62-78.

ZINGANO, Marco. Deliberação e vontade em Aristóteles. In: Filosofia Política - Nova Série. Porto Alegre, L\&PM, 1 (1997), p. 68-98.

\section{LIVRO EM HOMENAGEM AO SÉTIMO CENTENÁRIO DA MORTE DE DUNS SCOTUS}

\section{Commissione Internazionale Scotista}

\section{Annuncio}

La Commissio internationalis scotistica, per la celebrazione nel 2008 delcentenario della morte del beato Giovanni Duns Scoto, ha avviato la preparazione diun volume di studi originali intorno alla figura del Doctor subtilis ed allo scotismonelle sue varie articolazioni. II volume vuole essere anche un omaggio, di colleghi e discepoli, alla cara memoria del prof. César Saco ofm, che, inaspettatamente, ci ha lasciati il 19 febbraio 2005. II padre Saco è stato per 40 anni membro della Commissione scotista, della quale era attualmente Vice Presidente, e professore presso la Pontificia Università Antonianum. Gli studiosi che intendono offrire il loro contributo connesso, in qualche modo, con l'opera e la figura di Giovanni Duns Scoto, vogliano cortesemente farci giungere sollecita risposta della loro partecipazione al recapito in calce, notificandoci il titolo

del contributo che intendono offrire. Nel mese di settembre 2005 riceveranno ulteriori indicazioni per la preparazione del volume. Grato dell'attenzione, rivolgiamo il saluto più cordiale,

\section{Announcement}

The Commissio internationalis scotistica is compiling a series of original scholarly articles on the Blessed John Duns Scotus and on the various aspects of the Scotism. The volume is intended to be an early contribution to the 7th centenary of Scotus' death and also a homage to the memory of father César Saco, who unexpectedly died last February, after being a member of the Commissio scotistica for forty years. Scholars who wish to participate, are kindly requested to send the proposed title of their article together with their address. On September 2005, we will give further details to those who have adhered to this initiative.

Martín Carbajo Núñez, ofm

Prof. e vicedecano della PUA

Recapito / Contact address:

Martín Carbajo Núñez, ofm

Pontificia Università Antonianum

Via Merulana 124 b- 00185 Roma - Tel 0670373428

Email:cnmartin@ofm.org

antonianumfacteol@ofm.org 